Wolfgang Servatius

\title{
Gläubigereinfluss durch Covenants
}

\author{
Hybride Finanzierungsinstrumente im Spannungsfeld von Fremd- und \\ Eigenfinanzierung
}

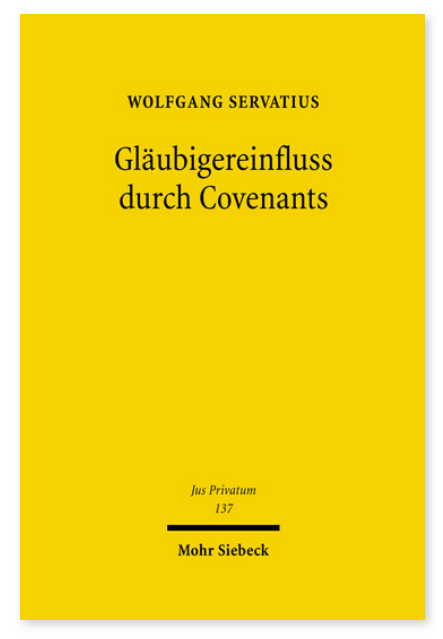

2008. XXVIII, 657 Seiten. JusPriv 137

ISBN 978-3-16-151214-8

DOI 10.1628/978-3-16-151214-8

eBook PDF $159,00 €$

ISBN 978-3-16-149739-1

Leinen $159,00 €$
Über Covenants in Kreditverträgen nehmen Gläubiger Einfluss auf die Unternehmensführung. Es wird vielfach dafür plädiert, dieses Zusammenrücken von Fremdkapitalgeber und finanziertem Unternehmen als Mittel zur Insolvenzvermeidung anzuerkennen und durch einen marktorientierten Regelungsrahmen auszugestalten. Wolfgang Servatius untersucht, wie sich die Fremdsteuerung von Unternehmen in das gesetzliche System von Fremd- und Eigenfinanzierung einfügt. Seine zentrale These lautet, diesen Außeneinfluss zu billigen, den betreffenden Kapitalgebern jedoch eine korrespondierende Verantwortung für das Unternehmen und seine sonstigen Gläubiger aufzuerlegen. Den Ansatz zur rechtlichen Verwirklichung dieser Verantwortung sieht er nicht in schadensrechtlichen Lösungen, sondern in einer Finanzierungsverantwortung. Auf der Grundlage des durch das MoMiG reformierten Rechts der Gesellschafterdarlehen entwickelt er eine rechtsformübergreifende Lösung, wonach mit der Einflussnahme eine insolvenzrechtliche Umqualifizierung des Finanzierungsbeitrags in QuasiEigenkapital einhergehen kann. Die hierdurch hergestellte Selbstbetroffenheit gewährleistet die in der Finanzierungstheorie anerkannte Ingangsetzungsfunktion des Eigenkapitals. Diejenigen, die sich der unternehmerischen Einflussnahme enthalten, dürfen darauf vertrauen, dass die Einflussnehmenden sachgerechte Entscheidungen treffen. Erstreckt man dies auf die nicht nur unerheblichen Einfluss nehmenden Fremdkapitalgeber, ist es innen verwehrt, in der Unternehmensinsolvenz die Rolle eines Insolvenzgläubigers einzunehmen.

Wolfgang Servatius Geboren 1969; Studium der Rechtswissenschaft in Mainz, Glasgow und München; 2003 Promotion; 2008 Habilitation; seit 2007 Vertretung des Lehrstuhls für Bürgerliches Recht und Unternehmensrecht an der Universität Regensburg.
Jetzt bestellen:

https://mohrsiebeck.com/buch/glaeubigereinfluss-durch-covenants-9783161512148?no_cache=1

order@mohrsiebeck.com

Telefon: +49 (0)7071-923-17

Telefax: +49(0)7071-51104 